Bull. Chem. Soc. Ethiop. 2017, 31(3), 397-409.

ISSN 1011-3924

(C) 2017 Chemical Society of Ethiopia and The Authors

Printed in Ethiopia

DOI: http://dx.doi.org/10.4314/bcse.v31i3.4

\title{
REMOVAL OF IMIDACLOPRID USING ACTIVATED CARBON PRODUCED FROM RICINODENDRON HEUDELOTII SHELLS
}

\author{
Kouakou Yao Urbain ${ }^{1 *}$, Essy Kouadio Fodjo ${ }^{1 *}$, Dembélé Ardjouma ${ }^{2}$, Brou Yapi Serge ${ }^{1}$, Ello \\ Serge Aimé ${ }^{1}$, Gouli Bi Irié Marc ${ }^{1}$ and Trokourey Albert ${ }^{1}$ \\ ${ }^{1}$ UFR SSMT, Physical Chemistry Laboratory, Felix Houphouet-Boigny University, 22 BP 582 \\ Abidjan 22, Côte d'Ivoire \\ ${ }^{2}$ Laboratoire Central d'Agrochimie et d'Ecotoxicologie (LCAE), Abidjan, Côte d'Ivoire
}

(Received June 20, 2017; Revised December 21, 2017; Accepted December 28, 2017)

\begin{abstract}
In this study, Ricinodendron heudelotii (akpi) shells are used as precursor to prepare activated carbon via chemical activation using phosphoric acid. The characterization of the obtained activated carbon is performed using X-ray diffraction (XRD), Boehm titration method and adsorption of acetic acid. The results show that the prepared activated carbon has a microstructure and a higher specific surface area $\left(1179 \mathrm{~m}^{2} / \mathrm{g}\right)$, suggesting that the acid treatment has a significant positive influence on its sorption properties. The maximum adsorption capacity and pollutant elimination efficiency are found to be $43.48 \mathrm{mg} / \mathrm{g}$ and $90 \%$, respectively. These results suggest that this low cost agent is an efficient tool to remove organic pollutants especially imidacloprid from wastewater.
\end{abstract}

KEY WORDS: Chemical activation, Adsorption, Activated carbon, Pesticide removal, Waste treatment

\section{INTRODUCTION}

Pesticides (insecticide, weed-killer, fungicide, etc.) are substances used in a wide range of applications especially in agriculture and households to eradicate pests including insects, wild grasses and vector-borne diseases. Although their use has revolutionized worldwide agricultural practices and forced back some diseases [1-3], pesticides can easily spread to all parts of environment thus, causing enormous ecosystem problems. In addition, they can bring resistance in some target species which can contribute to deteriorate the environment and to threaten human well-being [4]. For this reason a new class of insecticide has emerged. Imidacloprid is belonged to this new class used to control sucking insects including aphids, weevils, and many species of biting and stinging insects [5]. Because it has efficiently been used in agricultural application against pests and seed treatments, imidacloprid is one of the most used insecticides particularly in Ivory Coast (more than $60 \%$ of the insecticides used in cocoa crops) [6]. Moreover, it has been found to have a potential capability to contaminate soils, surface and ground water [7] and has been considered to be a fatal and persistent pesticide as its half-life $\left(\mathrm{DT}_{1 / 2}\right)$ is between 40 days and 288 days $[6,8]$.

Several methods including photocatalysis, electrocoagulation, biological treatment and disinfection are employed for pesticide removal [9-12]. However, these processes are somehow known to be in most cases limited, to use a long procedure or to be costly. To resolve these issues, adsorption has been widely investigated as one of the most prominent methods to remove such waste. The main material frequently employed in this technique is activated carbon which has the advantage to possess large surface area, excellent internal and external functions, large adsorption capacities and good adsorption kinetics [13-16]. The most commonly used precursors are agricultural wastes particularly coconut shell, rice bran, seed hull of the palm tree and olive stones $[14,16,17]$. The properties and the efficiency of these activated carbons depend mainly

*Corresponding author. E-mail: essykouadiofodjo@yahoo.fr, urbainyk@gmail.com

This work is licensed under the Creative Commons Attribution 4.0 International License 
on the characteristics of the precursor, preparation conditions and the type of activation. For this last point, chemical activation is largely employed in which phosphoric acid is widely used because of its non-polluting character, good quality of prepared carbon and ease of elimination of residues by water after carbonization [18].

In this work, we have prepared activated carbon from akpi shells. In fact, akpi is widely used in Ivorian cookery and traditional medicine. Herein, we are promoting a low-cost activated carbon from the waste of these shells which are considered irrelevant for human use. The obtained activated carbon has been chemical activated using phosphoric acid and has been applied for imidacloprid removal in aqueous media. The results suggest that this activated carbon is efficient adsorption agent for organic pollutant removal in aqueous media.

\section{EXPERIMENTAL}

\section{Raw material}

Akpi-shells were freely provided by women from the region of Sikensi (south Ivory Coast) during the harvest of akpi almond.

\section{Reagents}

All reagents were of analytical grade and were used as received without any purification. Sodium hydroxide (99\%) and sodium chloride (98\%) were purchased from Scharlau (European Union), orthophosphoric acid $\left(\mathrm{H}_{3} \mathrm{PO}_{4}, 85 \%\right)$ and sodium carbonate $\left(\mathrm{Na}_{2} \mathrm{CO}_{3}, 99.9 \%\right)$ from Merck (Germany), sodium bicarbonate $\left(\mathrm{NaHCO}_{3}, 99.7 \%\right)$ from Prolabo (France), acetic acid (96\%), hydrochloric acid (37\%) from Carlo Erba (France) and, imidacloprid standard (98\%) was provided by Dr. Ehrenstorfer GmbH (Germany).

\section{Preparation of activated carbon}

Akpi shells are thoroughly washed with deionized water in order to eliminate any dirt and dried for $24 \mathrm{~h}$ at $110{ }^{\circ} \mathrm{C}$. After this step, $20 \mathrm{~g}$ of these dried shells are kept for $48 \mathrm{~h}$ in $10 \mathrm{~mL}$ of orthophosphoric acid $(14.8 \mathrm{M})$. The obtained samples are carbonized at $500{ }^{\circ} \mathrm{C}$ in nitrogen gas for $2 \mathrm{~h}$ in a muffle furnace (Nabertherm West Germany). The resulting samples are cooled and then repeatedly washed with deionized water until $\mathrm{pH} 7$ to remove the activation reagent and undesired products. The samples are dried again for $2 \mathrm{~h}$ and stored in desiccator. The final product is crushed to have a granular form $(\sim 1 \mathrm{~mm})$ of activated carbon from akpi. The obtained product is denoted as akpi activated carbon (AAC). For further investigation, akpi non-activated carbon (ANC) was prepared in a similar way without the orthophosphoric acid treatment step.

\section{Activated carbon characterization}

For the determination of the crystal structures, the samples of carbon were analyzed with a diffractometer using XRD (D8 Advance Bruker, Germany) with a germanium detector for the angle $2 \theta$ between $20-120^{\circ}$ with the scan rate of $0.01^{\circ} / \mathrm{s}$.

\section{Chemical characterization of activated carbon and surface properties}

The adsorption of acetic acid is used as easy, safe and economical method to determine the specific surface area of prepared activated carbon $[19,20]$. In this study, $20 \mathrm{~mL}$ of acetic acid with concentrations ranging from $0.01 \mathrm{M}$ to $0.1 \mathrm{M}$ are placed into flasks and $0.1 \mathrm{~g}$ of activated 
carbon is added in each flask under stirring at $200 \mathrm{rpm}$ till time $t$ (time to be optimized). Then, the obtained substrate was filtered. The titration of the samples with $\mathrm{NaOH}(0.1 \mathrm{M})$ using phenolphthalein as color change indicator was permitted to access the amount of adsorption $\mathrm{q}_{\mathrm{e}}$ at the time $t$ according to Equation (1):

$q_{e}(m g g)=\frac{\left(C_{0}-C_{e}\right)}{m} \times V$

where $C_{0}$ and $C_{\mathrm{e}}$ are the concentrations of acetic acid at initial and equilibrium time respectively, $V$ is the suspension volume and, $m$ the mass of activated carbon. Equation (2) (Langmuir equation) with Equation (3) are used to access the specific surface area of prepared activated carbon:

$q_{e}=\frac{q_{m} b c_{e}}{1+b c_{e}}$

$\mathrm{S}=\mathrm{q}_{\mathrm{m}} \cdot \mathrm{s} \cdot \mathrm{N}_{\mathrm{A}}$

where $\mathrm{q}_{\mathrm{m}}(\mathrm{mol} / \mathrm{g})$ is the maximal capacity of adsorption of the activated carbon, $\mathrm{s}=21 \AA^{2}$, is the surface area for acetic acid molecule and $\mathrm{N}_{\mathrm{A}}=6.2 \times 10^{23} \mathrm{~mol}^{-1}$, Avogadro constant.

Quantitative determination of functional groups of carbonized akpi shells was done using Boehm titration method. $50 \mathrm{~mL}$ of the solutions of $\mathrm{NaOH}, \mathrm{Na}_{2} \mathrm{CO}_{3}, \mathrm{NaHCO}_{3}$ and $\mathrm{HCl}$ with the same concentration of $0.05 \mathrm{M}$ were placed into $100 \mathrm{~mL}$ flasks, and $1 \mathrm{~g}$ of akpi activated carbon was added. The flasks were closed and stirred up to $48 \mathrm{~h}$ at room temperature $\left(27^{\circ} \mathrm{C}\right)$. After that, the samples were centrifuged to remove the carbon and $\mathrm{HCl}$ is used for the titrations of the $\mathrm{NaOH}, \mathrm{Na}_{2} \mathrm{CO}_{3}$ and $\mathrm{NaHCO}_{3}$ solutions. This titration with $\mathrm{HCl}$ provides information about the surface character.

In order to determine the $\mathrm{pH}$ of the activated carbons, $3 \mathrm{~g}$ of activated carbon were added to a flask containing $60 \mathrm{~mL}$ of deionized water and then covered. The mixture was gently brought to boil for $3 \mathrm{~min}$. After filtration and cooling of the solutions at room temperature, the $\mathrm{pH}$ was determined by $\mathrm{pH}$-meter. However, ash contents were determined by following method: firstly the carbon was ground and sieved in order to have samples with a $0.5 \mathrm{~mm}$ size. Secondly, $1 \mathrm{~g}$ of this sample was placed in tarred porcelain crucible and put in a furnace at $500{ }^{\circ} \mathrm{C}$ for $2 \mathrm{~h}$, and finally cooled at room temperature and reweighed.

\section{HPLC analysis of imidacloprid}

The concentration of imidacloprid was analyzed using a HPLC system Shimadzu Prominence LC-20A series (SHIMADZU, Japan) equipped with UV-Vis detector SPD-20A (set on $252 \mathrm{~nm}$ ). The column used is Shimadzu VP-ODS C18 $(250 \times 4.6 \mathrm{~mm})$. The mobile phase was acetonitrile $/ 0.01 \%$ acetic acid-water $(40: 60, \mathrm{v} / \mathrm{v})$ at a flow rate of $1.0 \mathrm{~mL} / \mathrm{min}$, and the injected volume was $20 \mu \mathrm{L}$. Under this operating condition, the retention time of imidacloprid was found to be $5.82 \mathrm{~min}[6]$.

In HPLC measurements, $0.1 \mathrm{~g}$ of activated carbon was mixed with $20 \mathrm{~mL}$ of 10 and $20 \mathrm{mg} / \mathrm{L}$ of the standard imidacloprid solution in two different conical flasks. These mixtures were left under stirring at $200 \mathrm{rpm}$ for different times of $0,0.25,0.5,0.75,1,1.25,1.30,2$ and $3 \mathrm{~h}$. After each contact time, the solution was filtered and the final concentrations of imidacloprid were determined by HPLC. 


\section{RESULTS AND DISCUSSION}

\section{Physico-chemical characteristics of the activated carbon}

\section{Performance of the preparation process}

To evaluate the performance of the preparation and activation process, the product yield was investigated. For this purpose a weight $\left(\mathrm{W}_{1}\right)$ of akpi-shell is carbonized at $500^{\circ} \mathrm{C}$. After cooling, the carbon was finally dried to a constant weight $\left(\mathrm{W}_{2}\right)$. The yield decrease is obtained using Equation (4):

$\%$ Yield $=\frac{W_{1}-W_{2}}{W_{1}} \times 100$

According to Table 1, the yield is found to be around 35\%. The ash content of the akpi carbonaceous material gives $2.35 \%$ and $3.88 \%$ for ANC and AAC, respectively. This increase in ash with activation may be due to the presence of polyphosphates from the activation with $\mathrm{H}_{3} \mathrm{PO}_{4}[18]$.

Table 1. Mass yield of akpi-shell.

\begin{tabular}{|c|c|c|}
\hline $\begin{array}{c}\text { Weight (W1) of akpi-shell } \\
\text { before carbonization }(\mathrm{g})\end{array}$ & $\begin{array}{c}\text { Weight (W2) of akpi-shell after } \\
\text { carbonization }(\mathrm{g})\end{array}$ & Mass percent of carbon $(\% \mathrm{C})$ \\
\hline 5 & 1.78 & 35.6 \\
\hline 10 & 3.43 & 34.3 \\
\hline 20 & 7.04 & 35.2 \\
\hline 50 & 17.5 & 34.9 \\
\hline
\end{tabular}

Specific surface area of prepared activated carbon

The adsorption of acetic acid onto carbon was performed to access the specific surface area of the carbons (Figure 1). The different parameters of the isotherm and the specific surface areas are summarized in Table 2. As displayed in this Table, without activation, the specific surface area of akpi carbon is around $401 \mathrm{~m}^{2} / \mathrm{g}$. This value is almost higher than those obtained with common activated carbon (Table 3). This result denotes that the akpi shells can be a good precursor to prepare activated carbon. Furthermore, this study revealed that the specific surface area of akpi carbon increase with activation. This increase in specific surface area of the produced AAC should be due to the activation agent. Indeed, according to the literature, chemical activation of carbon considerably improves the specific surface $[18,21]$.

Table 2. Adsorption of acetic acid parameters using Langmuir isotherms.

\begin{tabular}{|c|c|c|c|}
\hline Carbon & $\mathrm{R}^{2}$ & $\mathrm{q}_{\mathrm{m}}(\mathrm{mol} / \mathrm{g})$ & Surface area $\left(\mathrm{m}^{2} / \mathrm{g}\right)$ \\
\hline AAC & 0.993 & $9.328 \times 10^{-3}$ & 1179 \\
\hline ANC & 0.990 & $3.175 \times 10^{-3}$ & 401 \\
\hline
\end{tabular}

Table 3.Surface area of prepared carbon without activation.

\begin{tabular}{|l|c|c|}
\hline Carbon & Specific surface area $\left(\mathrm{m}^{2} / \mathrm{g}\right)$ & Reference \\
\hline ANC & 401 & This study \\
\hline Non activated carbon from olive waste & $120-400$ & {$[20]$} \\
\hline Non activated carbon from peanut Shell & 147 & {$[22]$} \\
\hline Non activated carbon from green soya shell & 194 & {$[22]$} \\
\hline
\end{tabular}

Bull. Chem. Soc. Ethiop. 2017, 31(3) 


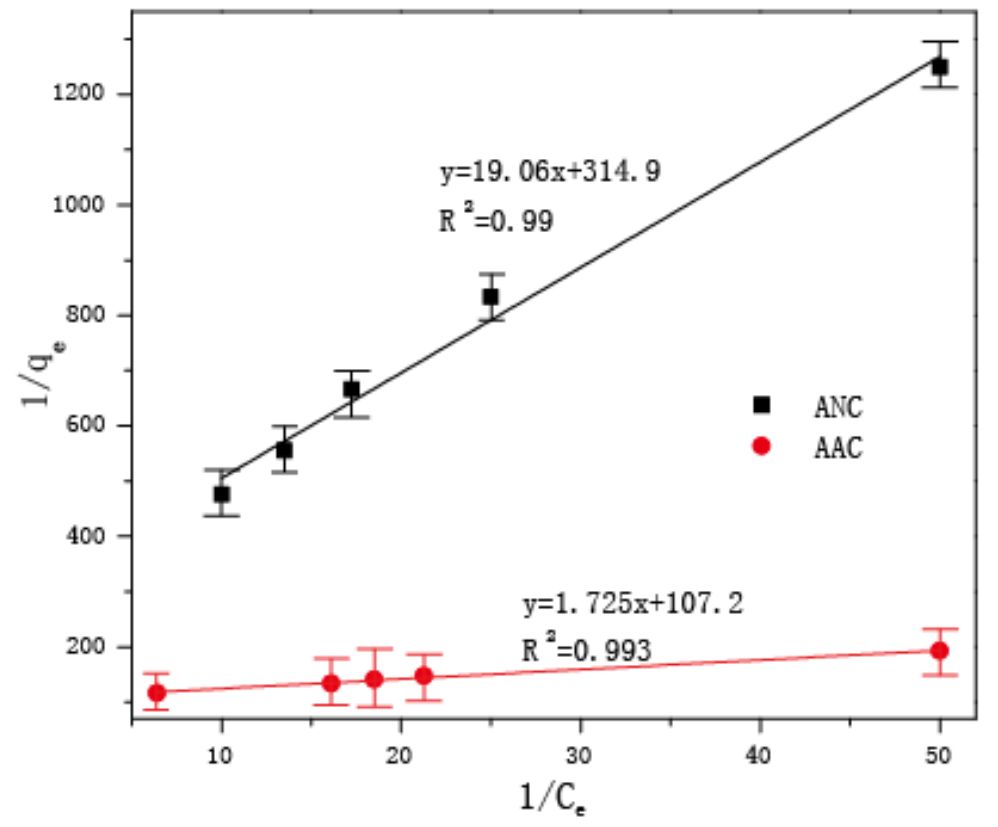

Figure 1. Langmuir plots for acetic acid adsorption onto AAC and ANC. Each data point represents the average value from three measurements. Error bars show the standard deviations.

Adsorbent surface properties

According to the previous studies [23, 24], the acidity or basicity of the surface is an important parameter in activated carbon application. These properties are evaluated by titration as described in the experiment part. It is known that $\mathrm{Na}_{2} \mathrm{CO}_{3}$ reacts with carboxyl and lactonic groups. The difference between the $\mathrm{n}_{\mathrm{CSF}}$ (the moles of different functions on the surface of the activated carbon) titrated with $\mathrm{NaOH}$ and the $\mathrm{n}_{\mathrm{CSF}}$ measured with $\mathrm{Na}_{2} \mathrm{CO}_{3}$ denotes the quantity of phenols on the surface. The difference between the groups titrated with $\mathrm{Na}_{2} \mathrm{CO}_{3}$ and those titrated with $\mathrm{NaHCO}_{3}$ is assumed to be lactones [25]. In order to determine the $\mathrm{pH}$ of the activated carbons, $3 \mathrm{~g}$ of activated carbon were added to a flask containing $60 \mathrm{~mL}$ of deionized water and then covered. The mixture was gently brought to boil for $3 \mathrm{~min}$. After filtration and cooling of the solutions at room temperature, the $\mathrm{pH}$ was determined by $\mathrm{pH}$-meter. As displayed in Table 4, the $\mathrm{pH}$ values indicate acid and neutral character of AAC and ANC, respectively. The distribution of functional groups according to Boehm titration method is consistent with the $\mathrm{pH}$ values. This high acidic surface of AAC is mainly due to the chemical activation which can increase carboxylic group [18]

Table 4. Surface properties of carbons.

\begin{tabular}{|l|c|c|c|c|c|c|}
\hline $\begin{array}{l}\text { Carbon } \\
\text { type }\end{array}$ & $\begin{array}{c}\text { carboxylic } \\
(\mathrm{mmol} / \mathrm{g})\end{array}$ & $\begin{array}{c}\text { Lactone } \\
(\mathrm{mmol} / \mathrm{g})\end{array}$ & $\begin{array}{c}\text { Phenolic } \\
(\mathrm{mmol} / \mathrm{g})\end{array}$ & $\begin{array}{c}\text { Total acidic sites } \\
(\mathrm{mmol} / \mathrm{g})\end{array}$ & $\begin{array}{c}\text { Total basic sites } \\
\mathrm{mmol} / \mathrm{g})\end{array}$ & $\mathrm{pH}$ \\
\hline AAC & 0.69 & 0.63 & 0.05 & 1.37 & 0.88 & 5.5 \\
\hline ANC & 0.24 & 0.40 & 0.18 & 0.82 & 0.96 & 7.2 \\
\hline
\end{tabular}


$X$-ray diffraction $(X R D)$

The crystalline structure of the prepared activated carbon was explored using XRD technique. Figure 2A shows the typical XRD pattern of both prepared ANC and AAC. As can be seen, both $\mathrm{ANC}$ and AAC have similar profile. This result suggests that the chemical activation has no effect on the structure of AAC. However, the sharp peak at $2 \theta=30^{\circ}$ in the case of AAC, can be attributed to the presence of microcrystalline carbon fragments, thus resulting in better layer alignment and amorphous structure [26, 27]. The obtained carbon can therefore be identified as amorphous structure and may be a good adsorbent.
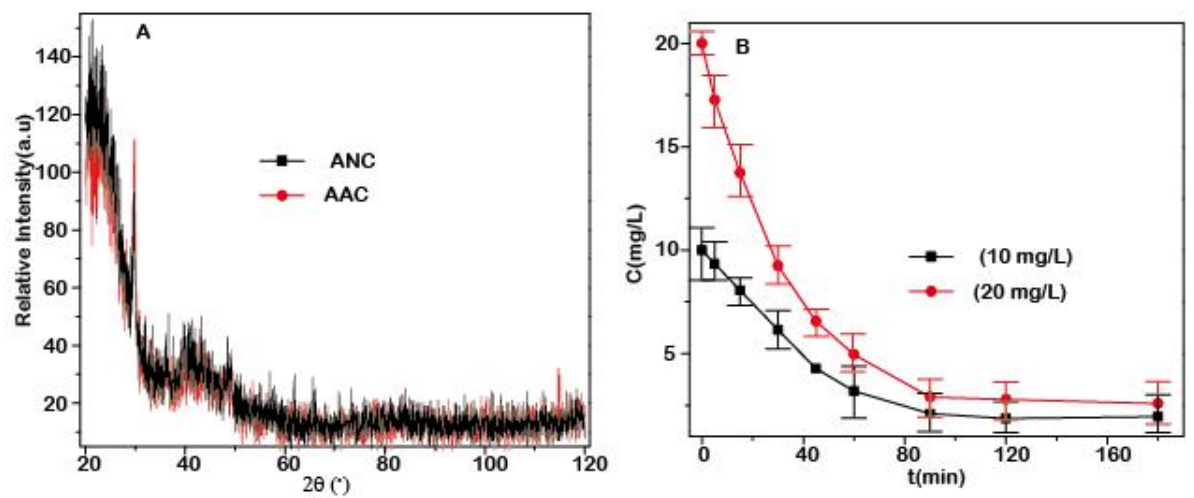

Figure 2. (A) XRD profiles of ANC and AAC and (B) adsorption kinetic of imidacloprid on AAC. Each data point represents the average value from three measurements. Error bars show the standard deviations.

\section{Kinetic adsorption study}

To determine the kinetic order and the time required to reach adsorption equilibrium, the adsorption kinetic study of imidacloprid on AAC is carried out at room temperature with two different concentrations of imidacloprid solution. For this purpose, $0.1 \mathrm{~g}$ of activated carbon was mixed with $20 \mathrm{~mL}$ of 10 and $20 \mathrm{mg} / \mathrm{L}$ of standard imidacloprid solution in two different conical flasks. These mixtures were left under stirring at $200 \mathrm{rpm}$ for different times of $0,0.25,0.5$, $0.75,1,1.25,1.30,2$ and $3 \mathrm{~h}$. After each contact time, the solution was filtered and the final concentrations of imidacloprid were determined by HPLC. The amount of adsorbed imidacloprid onto AAC is calculated according to Equation (5) [28].

$q_{t}=\frac{\left(C_{0}-C_{t}\right)}{m} \times V$

where $q_{t}(\mathrm{mg} / \mathrm{g})$ is the amount of adsorbed imidacloprid per unit mass of akpi-shell activated carbon, $C_{0}$ and $C_{t}$ are the initial and the final concentration (ppm) of imidacloprid, respectively, $V$ is the initial solution volume (L), $m$ the mass of the activated carbon $(\mathrm{g})$.

Figure $2 \mathrm{~B}$ displays the adsorption study of the imidacloprid on AAC for different times. As exhibited, the process of adsorption is relatively fast and reaches equilibrium within 90 min. This result may suggest the efficiency of the prepared activated carbon and $90 \mathrm{~min}$ can be used as equilibrium time.

Moreover, to acquire the order of the imidacloprid adsorption kinetic, three kinetic models were used. 
Pseudo-first order with equation:

$\ln \mathrm{C}-\ln \mathrm{C}_{0}=-\mathrm{k}_{1} \mathrm{t}$

Pseudo-second order which can be formulated as

$1 / \mathrm{C}-1 / \mathrm{C}_{0}=\mathrm{k}_{2} \mathrm{t}$

Intraparticle diffusion with equation

$\mathrm{q}_{\mathrm{t}}=\mathrm{k}_{\mathrm{i}} \mathrm{t}^{1 / 2}$

where $\mathrm{q}_{\mathrm{t}}$ is the amount of imidacloprid adsorbed at the time $\mathrm{t}, \mathrm{C}_{0}$ and $\mathrm{C}$ are the initial and any time concentrations of imidacloprid respectively and, the first rate constants $\mathrm{k}_{\mathrm{i}}$ for diffusion, $\mathrm{k}_{1}$ for pseudo-first order model and $\mathrm{k}_{2}$ for the model of pseudo-second order.

Table 5. Obtained parameters of the three applied kinetic models for imidacloprid adsorption.

\begin{tabular}{|c|c|c|c|c|c|c|c|c|c|}
\hline \multirow{2}{*}{$\begin{array}{c}\text { Initial } \\
\begin{array}{c}\text { concentration } \\
(\mathrm{mg} / \mathrm{L})\end{array}\end{array}$} & \multicolumn{3}{|l|}{ Pseudo-first order } & \multicolumn{3}{|l|}{ Pseudo-second order } & \multicolumn{3}{|c|}{ Intraparticle diffusion } \\
\cline { 2 - 10 } & $\begin{array}{c}\mathrm{k}_{1} \\
\left.\mathrm{~min}^{-1}\right)\end{array}$ & $\mathrm{R}^{2}$ & $\mathrm{P}$ & $\begin{array}{c}\mathrm{k}_{2} \\
\left(\mathrm{~g} \cdot \mathrm{mg}^{-1} \cdot \mathrm{min}^{-1}\right)\end{array}$ & $\mathrm{R}^{2}$ & $\mathrm{P}$ & $\begin{array}{c}\mathrm{k}_{\mathrm{i}} \\
\left(\mathrm{g}_{\mathrm{mg}} \mathrm{mg}^{-1} \cdot \mathrm{min}^{-1 / 2}\right)\end{array}$ & $\mathrm{R}^{2}$ & $\mathrm{P}$ \\
\hline 20 & 0.021 & 0.992 & 4.58 & 0.013 & 0.998 & 5.35 & 0.393 & 0.98 & 13.22 \\
\hline 10 & 0.018 & 0.993 & 3.37 & 0.018 & 0.981 & 8.28 & 0.184 & 0.96 & 21.36 \\
\hline
\end{tabular}

$\mathrm{k}$ : rate constant, $\mathrm{R}^{2}$ : correlation coefficients and $\mathrm{P}$ : percentage deviation.

The curves of each kinetic model were plotted (Figure 3) and the different parameters are given in Table 5. As can be observed, the intraparticle diffusion model gives the smallest correlation coefficients. However, it seems that all of these models are applicable as for each model the coefficient of correlation is higher than 0.96 . It is therefore necessary to use a test of normalized percent deviation (P) defined by Equation (9).

$P=\left(\frac{100}{N}\right) \sum\left(\frac{\left|q_{t, \exp }-q_{t, c a l}\right|}{q_{t, \exp }}\right)$

where $\mathrm{q}_{\mathrm{t}, \exp }$ is the experimental amount of adsorbed imidacloprid and $\mathrm{q}_{\mathrm{t}, \mathrm{cal}}$ the corresponding predicted adsorbed amount according to the applied model with the best fitted parameters at the same time $\mathrm{t}$, and $\mathrm{N}$ the number of data points.

From the Table 5, it can be seen that the lower value of $\mathrm{P}$ is from pseudo-first order. This result proves that pseudo-first order well describes the kinetic adsorption of imidacloprid on AAC. The results from this work are in good agreement with those reported in the literature [29, 30].

\section{Adsorption study at equilibrium}

For further investigation of the adsorption study at equilibrium, $0.5 \mathrm{~g}$ of fabricated activated carbon was mixed with different imidacloprid concentrations ranging from 1.25 to $50 \mathrm{mg} / \mathrm{L}$ in $100 \mathrm{~mL}$ flasks. Then the mixtures were left under stirring at $200 \mathrm{rpm}$ for $90 \mathrm{~min}$ at room temperature [31]. After equilibrium time, the samples were filtered and analyzed using HPLC. The amount of adsorbed imidacloprid per unit mass of AAC at equilibrium, $q_{e}$, was calculated using Equation (2). The adsorption isotherm of imidacloprid onto fabricated activated carbon was carried out at room temperature $\left(27^{\circ} \mathrm{C}\right)$ for $90 \mathrm{~min}$ (Figure $\left.4 \mathrm{~A}\right)$. As exhibited, the adsorbed amount of imidacloprid increases with the concentrations of imidacloprid at equilibrium. This adsorption of imidacloprid may therefore be classified as L-type and may suggest that imidacloprid has a good affinity for AAC. This result denotes that there is no competition between imidacloprid and the solvent at the sites of adsorption [32]. 

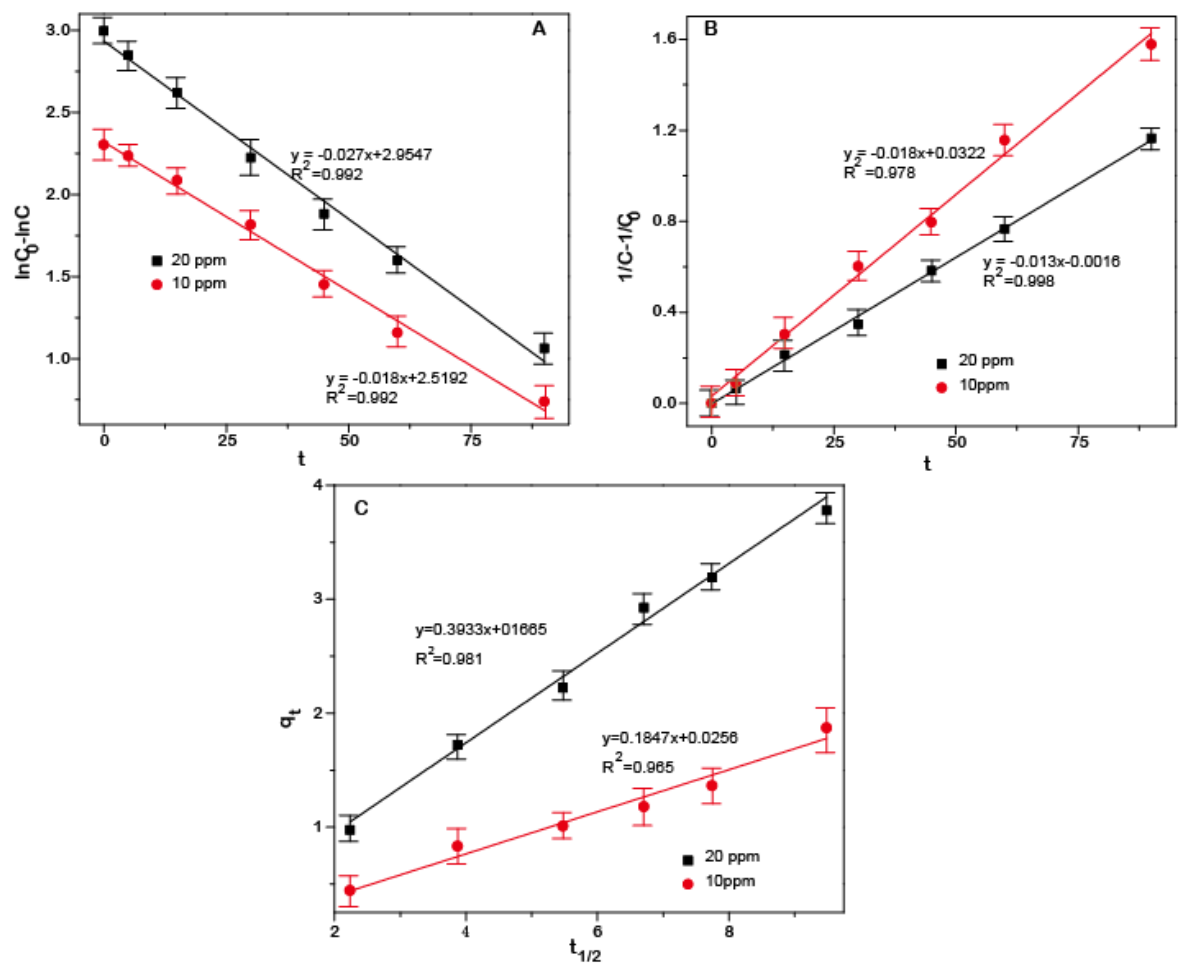

Figure 3. Kinetic model for (A) pseudo-first order, (B) pseudo-second order and (C) intraparticle diffusion. Each data point represents the average value from three measurements. Error bars show the standard deviations.

Several models are commonly used to assess the adsorbent capacity to remove pollutants from aqueous solutions. However, the most used models are Langmuir, Freundlich and Temkin [33]. Their equations are respectively given below (Equation 10-12):

$$
\frac{1}{q_{e}}=\frac{1}{b q_{m}} \frac{1}{C_{e}}+\frac{1}{q_{m}}
$$

$\ln q_{e}=\ln K_{F}+\frac{1}{n} \ln C_{e}$

$q_{e}=\frac{R T}{\Delta Q} \ln K_{0}+\frac{R T}{\Delta Q} \ln C_{e}$

where Ce (ppm) and qe (mg. $\left.\mathrm{g}^{-1}\right)$ are the concentration and the amount of the adsorbed imidacloprid per unit mass of activated carbon at equilibrium respectively, $b\left(\mathrm{~L}_{\mathrm{mg}} \mathrm{m}^{-1}\right)$ and $\mathrm{q}_{\mathrm{m}}$ (mg. $\left.\mathrm{g}^{-1}\right)$ are the Langmuir constant and the maximum adsorption capacity of the adsorbent, $\mathrm{K}_{\mathrm{F}}$ (mg. $\mathrm{L}^{-1}$ ) and $1 / \mathrm{n}$ are the Freundlich constant and the heterogeneity factor, respectively, $\mathrm{T}$ temperature $(\mathrm{K}), \mathrm{K}_{0}$ is Temkin isotherm constants, $R\left(8.314 \mathrm{~J} \cdot \mathrm{mol}^{-1} \cdot \mathrm{K}^{-1}\right)$ is the universal gas constant and $\Delta \mathrm{Q}$ is heat of adsorption. 

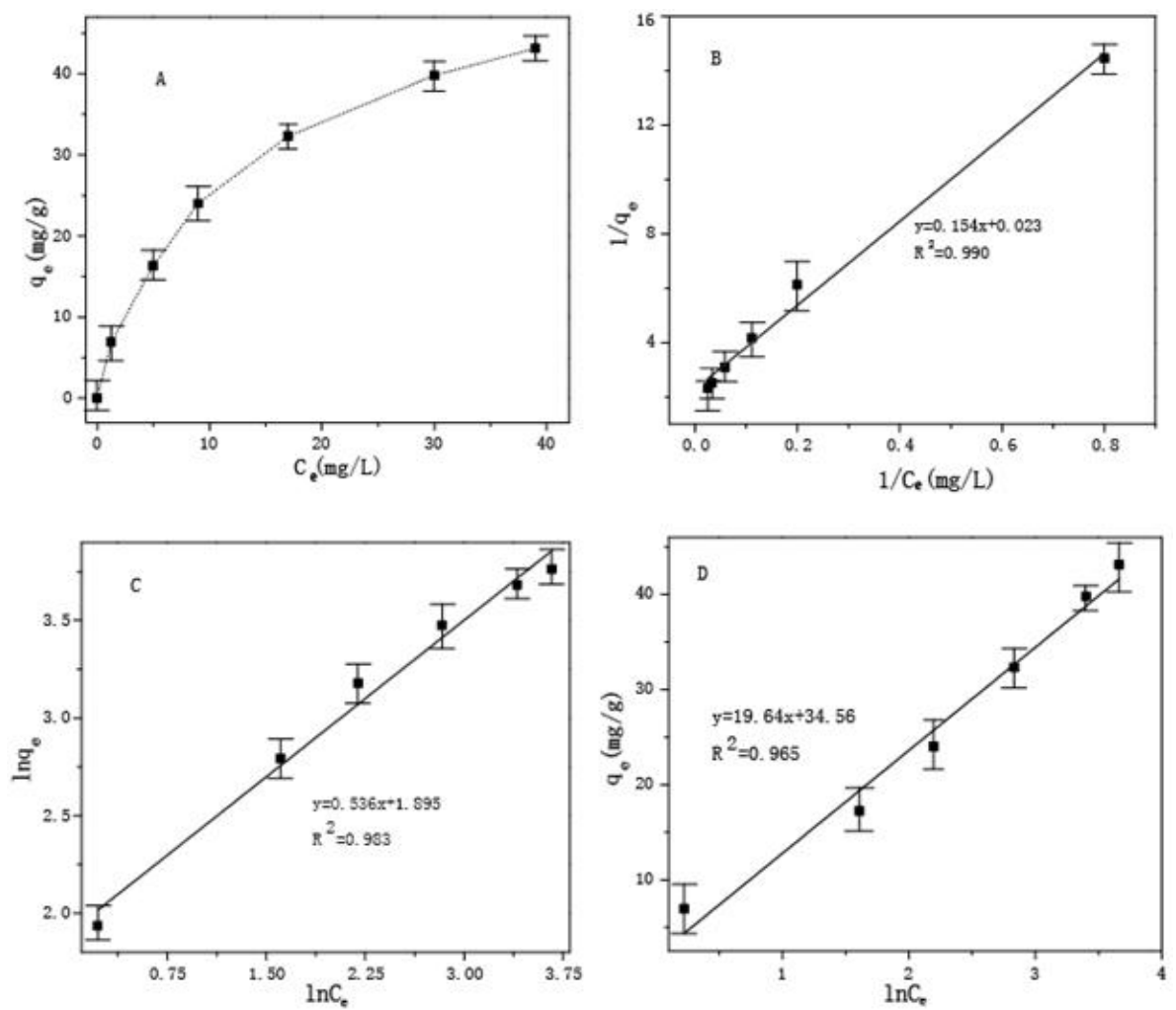

Figure 4. (A) Isotherm adsorption of imidacloprid onto akpi activated carbon, plots of imidacloprid adsorption onto AAC with (B) Langmuir model, (C) Freundlich model and (D) Temkin model. Each data point represents the average value from three measurements. Error bars show the standard deviations.

The different obtained isotherm parameters of Langmuir (Figure 4B), Freundlich (Figure 4C) and Temkin (Figure 4D) of imidacloprid adsorption onto AAC are summarized in Table 6. According to this Table, the obtained $\mathrm{R}^{2}$ from Freundlich and Langmuir models are higher than 0.98 suggesting that both Freundlich and Langmuir models fit well for the description of imidacloprid sorption on AAC. However, the obtained value $1 / \mathrm{n}=0.536<1$ implies that the adsorption process is chemical sorption [34]. On the other hand, the linear correlation of Temkin gives $\mathrm{R}^{2} \geq 0.96$, therefore this model can also be used to describe imidacloprid adsorption. The positive value of adsorption heat $(\Delta \mathrm{Q})$ using this model suggests that the adsorption process is exothermic model [33].

Table 6. Equilibrium adsorption isotherm parameters for imidacloprid sorption onto AAC.

\begin{tabular}{|c|c|c|c|c|c|c|c|}
\hline Model & Linear correlations $\left(\mathrm{R}^{2}\right)$ & $\mathrm{q}_{\mathrm{m}}(\mathrm{mg} / \mathrm{g})$ & $\Delta \mathrm{Q}(\mathrm{KJ} / \mathrm{mol})$ & $\mathrm{K}_{0}$ & $\mathrm{~b}$ & $\mathrm{Ln} \mathrm{k}$ & $1 / \mathrm{n}$ \\
\hline Langmuir & 0.990 & 43.48 & $\ldots$ & $\ldots$ & 0.1493 & $\ldots$ & $\ldots$ \\
\hline Temkin & 0.965 & $\ldots$ & 105.138 & 1.019 & $\ldots$ & $\ldots$ & $\ldots$ \\
\hline Freundlich & 0.983 & $\ldots$ & $\ldots$ & $\ldots$ & $\ldots$ & 1.895 & 0.536 \\
\hline
\end{tabular}


Influence of $\mathrm{pH}$ solution on the imidacloprid adsorption

To study the effect of $\mathrm{pH}$ on the imidacloprid adsorption on AAC, the experiments were carried out using $100 \mathrm{~mL}$ of $10 \mathrm{mg} / \mathrm{L}$ imidacloprid mixed with $0.5 \mathrm{~g}$ of activated carbon. The initial $\mathrm{pH}$ was adjusted to $2.1,3.35,4.25,6.9,8$ and 10.27 with $0.1 \mathrm{M} \mathrm{HCl}$ or $0.1 \mathrm{M} \mathrm{NaOH}$ (Figure 5A). The suspensions were then left under stirring at $200 \mathrm{rpm}$ for $90 \mathrm{~min}$ (equilibrium time) at room temperature and the amount of adsorbed imidacloprid was determined using Equation (13):

$\%$ rétention $=\frac{\left(C_{0}-C_{e}\right)}{C_{0}} \times 100$

where $C_{0}$ and $C_{\mathrm{e}}$ are the concentrations of imidacloprid at initial and equilibrium time respectively.

As shown in Figure 5A, the adsorbed amount of imidacloprid is low in acidic and basic media. The best adsorption process is obtained at $\mathrm{pH} 6.9$ suggesting that the $\mathrm{pH}$ significantly affects the adsorption process. Similar results were reported by Daneshvar et al. [31]. The $\mathrm{pH}$ effect may be due to the variation of the surface charge of AAC when the $\mathrm{pH}$ changes [35]. The competition between imidacloprid and $\mathrm{H}^{+}$ions in acidic or $\mathrm{OH}^{-}$ions in basic solution may also reduce the efficiency of AAC [36].
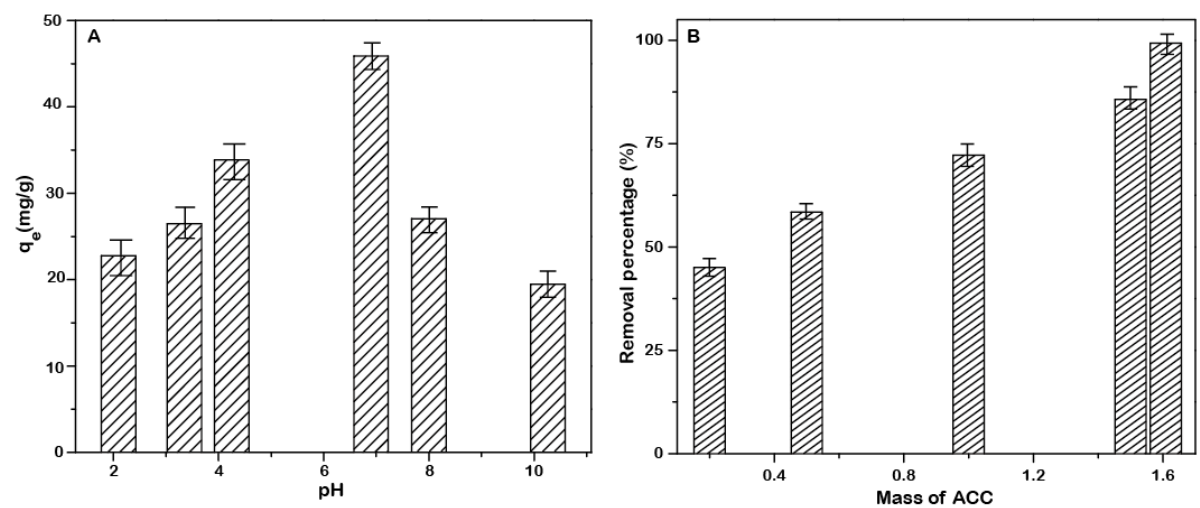

Figure 5. Influence of (A) $\mathrm{pH}$ and (B) adsorbent dose on the adsorption of imidacloprid. Each data point represents the average value from three measurements. Error bars show the standard deviations.

Influence of the amount of the activated carbon on the imidacloprid adsorption

The effect of sorbent dose on the uptake of imidacloprid was carried out using different masses of activated carbon $(0.1,0.2,0.5,1,1.5$ and $1.6 \mathrm{~g})$. The experiments were performed by stirring $20 \mathrm{~mL}$ of $10 \mathrm{mg} / \mathrm{L}$ of imidacloprid with the above different sorbent masses till the equilibrium time (90 min) and then the amount of adsorbed imidacloprid were determined (Figure 5B).

It is observed that the removal percentage of imidacloprid with AAC increases from 32.12 to $99.32 \%$ when the weight of adsorbent increases. This result infers that $80 \mathrm{~g} / \mathrm{L}$ of AAC can be used as activated carbon to eliminate more than $99 \%$ of imidacloprid in waste water.

Comparison of cost of manufactured carbons

An estimation of manufacturing cost of prepared carbons (AAC and ANC) is investigated (Table 7). Compared with other commercial activated carbons in a local market, the cost of the 
activated carbon produced with akpi shell is very low indicating that it should be possible to obtain a good activated carbon with very reasonable low-cost.

Table 7. Estimated cost of carbons product by akpi shell (Dollar US/ kg).

\begin{tabular}{|l|c|c|}
\hline Parameters & ANC & AAC \\
\hline Akpi shell and transportation & 0.36 & 0.36 \\
\hline Phosphoric acid & $*$ & 16.35 \\
\hline Power consumption & 29.62 & 29.62 \\
\hline Deionized water & 11.00 & 11.00 \\
\hline Package & 1.06 & 1.06 \\
\hline Total cost & 42.04 & 58.39 \\
\hline
\end{tabular}

\section{CONCLUSION}

In this work, activated carbon prepared from akpi shell using phosphoric acid as activation agent has been applied to remove imidacloprid from aqueous solutions. The obtained results show that this activated carbon exhibits a high specific surface area $\left(1179 \mathrm{~m}^{2} / \mathrm{g}\right)$. Even its non-activated displays a relatively high specific surface area $\left(401 \mathrm{~m}^{2} / \mathrm{g}\right)$ compared with those commonly used. In addition, it is found that up to $99 \%$ of imidacloprid can be removed using this fabricated activated carbon. According to these results, it is obvious that akpi shell may constitute a suitable precursor for the preparation of a low cost powerful activated carbon for organic compound removal. This fabricated activated carbon can therefore have an importance in diverse application such as wastewater treatment, chemical and pharmaceutical industry pollutant removal in different compartments of the environment.

\section{ACKNOWLEDGEMENTS}

The authors are thankful to LCAE members for providing the equipments of this study. EKF acknowledge financial support from Third World Academy of Science (TWAS) under the Grant No. 16-510 RG/CHE/AF/AC_G-FR3240293301.

\section{REFERENCES}

1. Osteen, C.D.; Fernandez-Cornejo, J. Economic and policy issues of U.S. agricultural pesticide use trends. Pest Manage. Sci. 2013, 69, 1001-1025.

2. Bentum, J.; Essumang, D.; Dodoo, D. Lindane and propuxur residues in the top soils of some cocoa growing areas in five districts of the Central Region of Ghana. Bull. Chem. Soc. Ethiop. 2006, 20, 193-199.

3. Bedassa, T.; Gure, A.; Megersa, N. The QuEChERS analytical method combined with low density solvent based dispersive liquid-liquid microextraction for quantitative extraction of multiclass pesticide residues in cereals. Bull. Chem. Soc. Ethiop. 2017, 31, 1-15.

4. Alavanja, M.C.R.; Ross, M.K.; Bonner, M.R. Increased cancer burden among pesticide applicators and others due to pesticide exposure. CA: A Cancer J. Clinicians 2013, 63, 120 142.

5. Jeschke, P.; Nauen, R. Neonicotinoids-from zero to hero in insecticide chemistry. Pest Manage. Sci. 2008, 64, 1084-1098.

6. Kouakou, Y.U.; Dembélé, A.; Ello, A.S.; Brou, Y.S.; Yao, B.L.; Trokourey, A. Study of adsorption of imidacloprid onto two different textures of soils. Int. J. Biol. Chem. Sci. 2015, 9, 472-482. 
7. Bajeer, M.A.; Nizamani, S.M.; Sherazi, S.T.H.; Bhanger, M.I. Adsorption and leaching potential of imidacloprid pesticide through alluvial soil. Am. J. Anal. Chem. 2012, 3, 604611.

8. Proenca, P.; Teixeira, H.; Castanheira, F.; Pinheiro, J.; Monsanto, P.V.; Marques, E.P.; Vieira, D.N. Two fatal intoxication cases with imidacloprid: LC/MS analysis. Forensic Sci. Int. 2005, 153, 75-80.

9. Humbert, H.; Gallard, H.; Suty, H.; Croué, J.-P. Natural organic matter (NOM) and pesticides removal using a combination of ion exchange resin and powdered activated carbon (PAC). Water Res. 2008, 42, 1635-1643.

10. Abdel-Gawad, S.A.; Baraka, A.M.; Omran, K.A.; Mokhtar, M.M. Removal of some pesticides from the simulated waste water by electrocoagulation method using iron electrodes. Int. J. Electrochem. Sci. 2012, 7, 6654-6665.

11. Maghanga, J.K.; Segor, F.K.; Etiégni, L.; Lusweti, J. Electrocoagulation method for colour removal in tea effluent: A case study of Chemomi tea factory in rift valley, Kenya. Bull. Chem. Soc. Ethiop. 2009, 23, 371-381.

12. Gomoro, K.; Zewge, F.; Hundhammer, B.; Megersa, N. Fluoride removal by adsorption on thermally treated lateritic soils. Bull. Chem. Soc. Ethiop. 2012, 26, 361-372.

13. Gupta, V.K.; Gupta, B.; Rastogi, A.; Agarwal, S.; Nayak, A. Pesticides removal from waste water by activated carbon prepared from waste rubber tire. Water Res. 2011, 45, 4047-4055.

14. Kannan, A.; Thambidurai, S. Removal of hexavalent chromium from aqueous solution using activated carbon derived from palmyra palm fruit seed. Bull. Chem. Soc. Ethiop. 2008, 22, 183-196.

15. Bello, O.S.; Olusegun, O.A.; Njoku, V.O. Fly ash: An alternative to powdered activated carbon for the removal of eosin dye from aqueous solutions. Bull. Chem. Soc. Ethiop. 2013, 27, 191-204.

16. Okeola, O.; Odebunmi, E.; Ameen, O. Comparison of sorption capacity and surface area of activated carbon prepared from Jatropha curcas fruit pericarp and seed coat. Bull. Chem. Soc. Ethiop. 2012, 26, 171-180.

17. Ikhuoria, E.; Onojie, O. Binding of nickel and zinc ions with activated carbon prepared from sugar cane fibre (Saccharum officinarum L.). Bull. Chem. Soc. Ethiop. 2007, 21, 151-156.

18. Moreno-Castilla, C.; Carrasco-Marín, F.; López-Ramón, M.V.; Alvarez-Merino, M.A. Chemical and physical activation of olive-mill waste water to produce activated carbons. Carbon 2001, 39, 1415-1420.

19. Avom, J.; Mbadcam, J.K.; Matip, M.; Germain, P. Adsorption isotherme de l'acide acétique par des charbons d'origine végétale. Afr. J. Sci. Technol. 2001, 2, 1-7.

20. El-Hamouz, A.; Hilal, H.S.; Nassar, N.; Mardawi, Z. Solid olive waste in environmental cleanup: Oil recovery and carbon production for water purification. J. Environ. Manage. 2007, 84, 83-92.

21. Suzuki, R.M.; Andrade, A.D.; Sousa, J.C.; Rollemberg, M.C. Preparation and characterization of activated carbon from rice bran. Bioresour. Technol. 2007, 98, 19851991.

22. Ouattara, P.H.K.; Bi, M.I.G.; Kouakou, U.; Dembele, A.; Yapo, A.J.; Trokourey, A. Preparation and characterization of activated carbons based on peanut shell (Arachis hypogaea) green soya shell (Vigna radiata). Int. J. Sci. Res. (IJSR) 2014, 3, 933-937.

23. El-Sheikh, A.H.; Hilal, M.M.A.; Sweileh, J.A. Bio-separation, speciation and determination of chromium in water using partially pyrolyzed olive pomace sorbent. Bioresour. Technol. 2011, 102, 5749-5756.

24. Foo, K.; Hameed, B. Preparation, characterization and evaluation of adsorptive properties of orange peel based activated carbon via microwave induced $\mathrm{K}_{2} \mathrm{CO}_{3}$ activation. Bioresour. Technol. 2012, 104, 679-686. 
25. Pongener, C.; Kibami, D.; Rao, K.S.; Goswamee, R.L.; Sinha, D. Synthesis and characterisation of activated carbon from the biowaste of the plant Manihot esculenta. Chem. Sci. Trans. 2015, 4, 59-68.

26. Wimonrat, T.; Manop, S.; Phunsiri, H.; Saksit, C.; Chalerm, R. Preparation of activated carbon derived from Jatropha curcas fruit shell by simple thermo-chemical activation and characterization of their physico-chemical properties. Chem. Eng. Res. Des. 2011, 89, 335340.

27. Tang, Y.-b.; Liu, Q.; Chen, F.-y. Preparation and characterization of activated carbon from waste ramulus mori. Chem. Eng. J. 2012, 203, 19-24.

28. Ayranci, E.; Hoda, N. Adsorption of bentazon and propanil from aqueous solutions at the high area activated carbon-cloth. Chemosphere 2004, 57, 755-762.

29. Conway, B.E.; Ayranci, E.; Al-Maznai, H. Use of quasi-3-dimensional porous electrodes for adsorption and electrocatalytic removal of impurities from waste-waters. Electrochim. Acta 2001, 47, 705-718.

30. Niu, J.; Conway, B.E. Development of techniques for purification of waste waters: removal of pyridine from aqueous solution by adsorption at high-area C-cloth electrodes using in situ optical spectrometry. J. Electroanal. Chem. 2002, 521, 16-28.

31. Daneshvar, N.; Aber, S.; Khani, A.; Khataee, A. Study of imidaclopride removal from aqueous solution by adsorption onto granular activated carbon using an on-line spectrophotometric analysis system. J. Hazard. Mater. 2007, 144, 47-51.

32. Ayranci, E.; Hoda, N. Adsorption kinetics and isotherms of pesticides onto activated carboncloth. Chemosphere 2005, 60, 1600-1607.

33. Hamdaoui, O.; Naffrechoux, E. Modeling of adsorption isotherms of phenol and chlorophenols onto granular activated carbon: Part II. Models with more than two parameters. J. Hazard. Mater. 2007, 147, 401-411.

34. Crini, G. Kinetic and equilibrium studies on the removal of cationic dyes from aqueous solution by adsorption onto a cyclodextrin polymer. Dyes Pigm. 2008, 77, 415-426.

35. Muhammad Ashraf, B.; Shafi Muhammad, N.; Syed Tufail Hussain, S.; Muhammad Iqbal, B. Adsorption and leaching potential of imidacloprid pesticide through alluvial soil. Am. J. Anal. Chem. 2012, 3, 604-611.

36. Khaled, A.; El Nemr, A.; El-Sikaily, A.; Abdelwahab, O. Treatment of artificial textile dye effluent containing Direct Yellow 12 by orange peel carbon. Desalination 2009, 238, 210 232. 